\title{
Coherent Techniques for Solar Energy Generation and Applications
}

\author{
Parth Thakar \\ UG Student \\ Dwarkadas J. Sanghvi College of Engineering \\ Mumbai, India
}

\author{
Tushar Sawant \\ Assistant Professor \\ Dwarkadas J. Sanghvi College of Engineering \\ Mumbai, India
}

\begin{abstract}
As it is known that the sun is an unlimited source of energy, in today's world the solar energy has a different application on the basis of its conversion and usage. The major focus of this paper is on how to convert the solar energy i.e. the methods through which it can be implemented and employed. There arises a standard question which is "why solar energy?" and the answer to this is mentioned earlier that it is an unlimited source of energy. So during the daytime, an ample amount of energy could be stored and can be converted into electrical or thermal energy through the exploitation of the methods discussed below. This paper also sheds a light on the current scenario of the utilization and the need for solar energy in India. Furthermore, the paper also focuses on the various applications of it in the day to day life and their advantages. A small reflection on the topic Space-Based Solar Power [SBSP] has been put down in which it is discussed how the solar energy can be converted and utilized in space with its advantages and a relative comparison on how it is better as compared to the same conversion done on earth and also some of its disadvantages mentioning why is it not currently possible.
\end{abstract}

\section{Keywords}

Solar, PV cells, T panels, Space-Based Solar Power, Energy harvesting.

\section{INTRODUCTION}

As solar energy is a great source of energy and has various applications, it needs to be properly converted. In this paper, the process for the conversion is mentioned in detail. There are 2 main processes to do the same which are listed below.

- Photovoltaic CELl [PV CELL]: The photovoltaic cell is a semiconductor diode which can transform not only visible light falling on it but also Infrared [IF] and Ultraviolet [UV] rays into electrical energy by converting them into direct current. More in-depth description is discussed ahead in the paper. The PV cells are used to convert the solar energy into electrical energy only.

- THERMAL PANELS [T CELLS]: The Thermal panels or the [T CELLS] is an application to convert solar energy not into electrical energy but thermal energy. This thermal or heat energy has various applications in today's life. There are mainly 2 types of thermal panels or collectors namely the flat plate collectors and the evacuated tube collectors. These two have a different way or procedure of operation and applications but the final product is the converted thermal energy.

In this paper, it has also been discussed what is the current state of India with respect to the proper utilization and conversion of solar energy. As India is a tropical country there is an abundance of solar energy available which makes its usage to be highly beneficial as it is suffering through an acute shortage of electrical energy because of which power cuts have become common. The main reason for this is the theft of electricity. Furthermore, there are various sectors or areas in which the solar energy finds its applications like transportation, industrial sector's day to day usage etc. The main motive of using solar energy is its availability and other most important reason is that the construction, maintenance for the process of conversion and utilization is really less as compared to other sources. This method could also become more economical and feasible by combining the two technologies of PV cells and $\mathrm{T}$ panels which makes it more efficient. Lastly there a reflection of the Space-Based Solar Power system is manifested which shows why it can be more useful as compared to the process carried out on the ground but then it has many disadvantages as well.

\section{SYSTEM OVERVIEW}

\subsection{Photovoltaic Cell [P.V. Cell]}

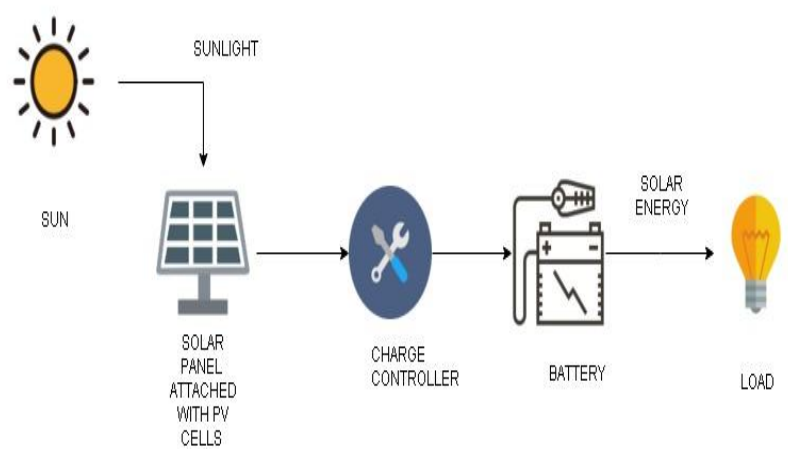

Figure 1. Basic Block Diagram For Implementation Of Pv Cells

The device used to transform or convert the discernible or the visible light into direct current [DC] is known as photovoltaic cell [P.V CELLL]. This PV cell is a specialized semiconductor diode which further transforms or converts infrared [IR] as well as ultraviolet rays [UV] into direct current electricity. As the trend continues to use alternate sources of energy for use the PV cells act as a constitutive part for the generation and conversion of solar electric energy which is the most trending and convenient option in today's world for energy usage conversion as well as harvesting. When the PV cells were first designed, they were developed by the usage of silicon combined with other elements to check if it makes any effect on the etiquettes of the electrons. But over a period of time with the advancements in technology and discovery of new materials like gallium arsenide [GaAs], copper indium diselenide [CIS] and cadmium telluride [CdTe] made the respective application more coherent. As mentioned before that the PV cell is a specialized semiconductor diode 
which has two simple types of semiconductor materials listed as:

- Positive [ p type semiconductor]

- Negative [n type semiconductor]

In the photovoltaic cell, the border or the boundary between these two semiconductors or the junction created is known as the $\mathrm{p}-\mathrm{n}$ junction. In the cell, the parts of these two types of semiconductors are placed together for its operations. The construction or the making of the PV cells happens in such a way that the PN junction is exposed to the direct sunlight from which the electricity can be generated. When the sunlight or any radiation may it be [IR] or [UV] falls on this $\mathrm{PN}$ junction, a certain amount voltage difference is generated. The electrodes connected in these cells convert this difference into the electric current. There are various uses of this PV cell in today's world because of its ability to generate power. They are operated by connecting to the solar panels or arrays. The utilization of these cells for the initiation of the electrical energy is known as photovoltaic. The main reason for using the photovoltaic cells is that they are environment-friendly, non-polluting and just require modicum amount of space and the sun which acts as the source to work. Once the PV cell is installed, power generation can be benefited with minimal maintenance.

\subsection{Solar Thermal Panels [T Panels]}

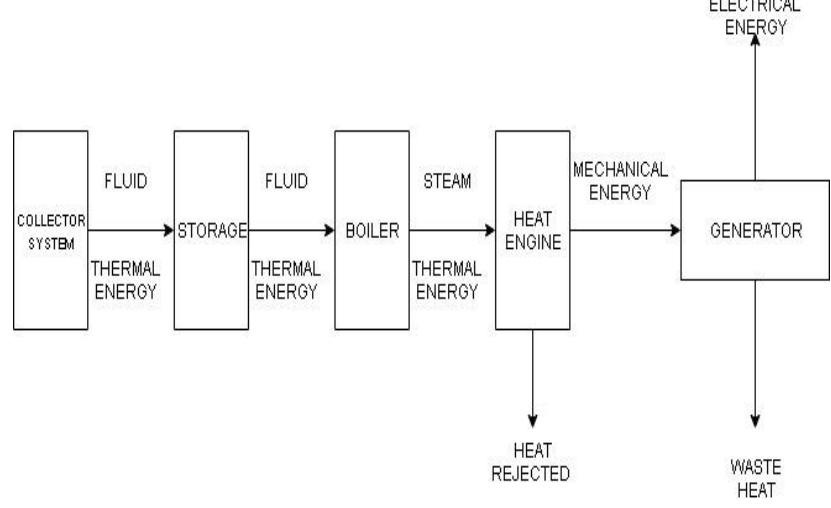

Figure 2. Basic Block Diagram For T Panels

Till now we saw that solar energy can be transformed or converted into electrical energy with the usage of the photovoltaic cells. This section we will look into solar thermal panels. The solar thermal panels can turn the sunlight into heat energy. As it turns out the solar thermal panels were the first one to be commercialized in the UK as an application for the solar energy. The solar thermal panels or also known as the solar collector is an appliance which manipulates the solar energy into heat energy as mentioned and can be used to heat up water in a cylinder. They can be fitted or installed on rooftops or ground space of any household or any infrastructure for this operation. The main liquids which are flowing inside the panels are the combination of water and antifreeze. There are two types of solar panels which are listed as follows:

- FlAT PLATE COLLECTORS: They consist of heat insulated backing, a transparent cover, dark absorbing surface and mainly a fluid which transports the converted heat energy from the absorber to the water tank. There are various materials from which the mentioned absorber can be constructed namely steel, aluminium, copper as well as polymers. Out of these copper turns out to be the most expensive one as it is the most durable and long lasting conductors. From these, the polymers are used in frosty climates because other elements such as silicon are not enduring and lack efficiency in such cases.

- EVACUATED[VACCUM TUBE] COLLECTORS: They do not resemble solar panels since their manufacturing is done by employing glass tubes which transfer the fluids who are responsible for accommodating heat energy inside the water in the tank. There are several pros and cons of these collectors, they are better working than the flat plate collectors in cold climate and on the other hand it reverses as in the case of summer because they work at the risk of overheating. The main reason for overheating in the vacuum tubes is because of its ignorance to loss of heat while in the flat plate collectors they tend to lose some heat. During snow melting period there exists a gap between the vacuum tubes which authorizes the snow to fall down and hence causing a minimum effect on its efficiency and in the case of excessive snow formation the snow melts due to the ignorance of the heat loss and balances the overheating.

\subsection{Feasible Utilization of Solar Energy using the Combination of Both PV Cells and T Panels}

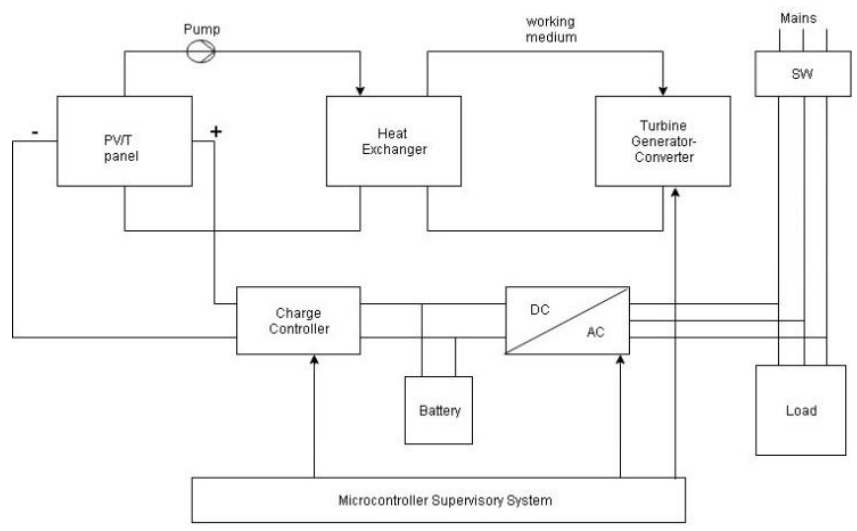

Figure 3. Block Diagram For Combination Of Both Solar And T Panels

As discussed above there are two methods which can be utilized for the conversion of solar energy to electrical energy and heat energy using PV cells and T panels respectively. But when the option of using PV cells is considered they convert the solar energy into electrical energy whose efficiency is quite moderate and the construction and maintenance cost of it is quite high. On the contrary when thermal panels or collectors have considered their construction is quite simple and the coherency of it is really high. So when the main motive is to utilize solar energy in more efficient way and gaining high power, it can be achieved by using a combination of T panels and PV cells as the energy converter can be in terms of heat/electrical form whose efficiency will be moderate but would result in being a most economic option. When these two technologies are combined the energy utilized by the panels can be increased by a great amount in a unique way such that the resulting power generated would be capable of cogenerating of heat and electric power. Another advantage of using them as a combination is that it would reduce the cost of production and maintenance as well as it 
will reduce the land area required to place them. As this pronounced approach uses both the technologies, hence designing and construction of this is very complex which makes it really difficult for implementation. To achieve it practically simulation and modelling techniques should be practiced. The System mentioned above is based on one of the simulation techniques which includes and incorporates apparatus like PV panels, charge controller, DC/AC converter etc. depending on the design.

\subsection{Applications and Advantages of Using Solar Energy in Today's World}

In the modern world as the energy conversion and its usage is becoming more and more crucial with an increase in usage due to increase in the population, it is necessary to shift to solar to make the environment green, sustainable and ecofriendly. The various applications of solar energy are discussed. Firstly, it can be applied in the field of transportation. It is an innovative option through which the sunrays can be used by PV cells for powering the transport. Buses, aircraft, trains and cars all of these can be operated by the utilization of solar energy which would lead to a positive impact by reducing the amount of $\mathrm{CO} 2$ emissions and other harmful substances. There are various examples of such successful transportation like the solar-powered aircraft namely solar impulse 2 which came into action and flew across the Pacific and yet another example of it can be seen in China where the solar energy operated buses are helping China to reduce the carbon footprint and hence making the transportation in the excessively populated cities like Beijing. Secondly, solar energy can be found in the category of powering consumer electronics. It is also known as wearable solar energy technology. There is a list of devices in the world which can be utilized more efficiently like cell phones, music speakers, thermostats, rechargeable flashlights, scientific calculators and even solar chargers which can be used to power any device once in sunlight for an example the Anker's power port which can power anything from a phone to a tablet or an e-reader as well. As society progresses in finding more renewable sources of energy, solar energy is the most convenient and feasible option for today's energy requirement. One of the most important and cost-saving applications of solar energy is the utilization of the solar panels on the rooftops of houses. As mentioned earlier that the applications of solar energy has applications like solar operated aircraft transportations and other purposes but the rooftop solar also plays a significant role because the rooftop solar saves a huge amount of money in the area of electricity because after assembling the rooftop solar with the help of the PV cells the solar rays can be directly converted into electrical energy and can be used for powering the household appliances. The only cost that will be there would be for the construction of rooftop solar and the maintenance for it which is very much coherent and feasible as compared to the electricity from the suppliers and would be a highly sustainable option. The applications stated in this section till now includes mostly the utilization of the PV cells but there are also various applications of the solar energy in the industrial sector which can be done by the operation of $\mathrm{t}$ panels as well. There are various industries which require a tremendous amount of heat energy for various operations. The heat energy is converted from the solar energy with the help of the $t$ panels as mentioned earlier. Going ahead the heat energy finds its applications in the industrial sector in processes like hot water usage up to 0 degrees for boilers. Then the heat energy is used for processes like pasteurization and the heat energy is also used for cleaning purposes in dairies and other sectors. Then arises a question why to use solar energy? This question is brought to justice by the advantages of using the solar energy which is stated as follows:

- First and foremost the solar energy is available almost in all parts of the world so it can be used very easily everywhere around the world.

- The main demand of the peak load time is in the morning and is the same time when the demand is met as the solar energy is available at the same time. Then the question arises that the solar energy is not available after sunset but this can be accomplished as there are many saving options for the energy converted. So the saved energy can be used even after the sunset.

- The main advantage of using the solar energy is that the cost used for setting up that is the construction and maintenance of the long-lasting peripherals is far more convenient and less as compared to the normal usage.

\subsection{Space Based Solar Power}

This is yet another method and one of the most out of the box to convert or transform solar energy into electrical energy and is known as the Space-Based Solar Power [SBSP]. This is an abstract of collecting solar energy directly from outer space and providing it directly to our planet earth. There are various merits of collecting solar energy from outer space which will be discussed further like more time for collection and a greater amount of energy conversion. The reason for a longer time period for the collection can be possible if the solar collector can be placed in the orbiting location where the sunlight is available for almost $24 \mathrm{hrs}$. There are also demerits to it like when the solar energy is converted and is distributed to the earth, there is an energy loss of 55 to $60 \%$ on the way due to the factors like reflection and absorption in the atmosphere. But this can be looked upon by the space based system as it can covert the solar energy into microwaves which can be redirected to the earth without any losses. But this can be achieved only by spending a massive amount. The Space-Based solar energy is considered a form of renewable energy as it is a great proposal for energy generation and conversion. Furthermore, the merits and the demerits of using Space-Based solar power are listed below.

- MERITS: The idea of utilization of Space-Based Solar Power (SBSP) sounds really attractive because space has more advantages as compared to the earth. First and foremost as mentioned earlier as well that there is no night in space and the solar energy is available 24 hours which makes it very convenient for the larger amount of energy conversion and transmission. Then another merit of using the SBSP system is that there are no obstructions as compared to the solar energy conversion on earth. When the sunrays were absorbed by the panels there were obstructions in the way of the sunlight like clouds the layers and gases of the atmosphere due to which there was a lower amount of energy but in space, there are no such obstructions. Moving ahead there won't be any interference of the flora and fauna and the wildlife in the space which is also a factor to consider. The most important reason for using the [SBSP] is that if it is operated on a large scale and at minimal 
altitudes, the harmful solar radiations reaching the earth's surface can be reduced therefore reducing the main issued of global warming.

- DEMERITS: There are numerous demerits associated with the utilization of SBSP which make it almost impossible for the implementation. The most major and important reason for not opting for it is the cost associated with each of its processes. This includes the making of one such solar collector or a satellite which can absorb the rays and transmit them to the earth. The cost would also include the making of and the maintenance of the extravagant size receiver on the ground to collect the waves distributed from the space. Addition to the cost, there is also a major hazard in space like the space debris in the orbit which can potentially destroy the whole Space-Based Solar Power system.

\subsection{Current Scenario of India with respect to Solar Energy Generation.}

The main need for solar energy generation is already met by the day sunlight from the sun in most of the places which adds an advantage and diminishes the peak energy costs which further helps in the reduction of energy and power bills. As it is known that India is a tropical country and it gets nominal radiation for near about 300 days in a year summing up to 3000 hours of sunshine which can generate an extravagant amount of energy equivalent to 5000 trillion $\mathrm{kWh}$. Mostly all the parts and regions in India receive $4-7 \mathrm{kWh}$ radiation per square meter which can generate energy equivalent to 2300 to 3200 hours/days depending on the location. Over the passing years the electricity losses in distribution and the transmission as well as reached its peak with the worst proportion of $24.7 \%$ during the year of 2010-2011. This shows that India is in an urge for a shortfall of peak power which is about $13 \%$ and can be achieved by reducing the loss of electricity due to theft. The loss of electricity due to theft is a major problem in India and is found mostly in the urban areas of India. The loss of electricity due to theft is so high in India that it sums up to $1.5 \%$ of the GDP of India. This creates a shortage of electricity, as a result, there are power cuts in many regions and hence is a common problem in India

Table 1. Solar Energy Generation in India [13]

\begin{tabular}{|c|c|c|c|}
\hline $\begin{array}{c}\text { Sr. } \\
\text { No }\end{array}$ & State & $\begin{array}{c}\text { Photovoltaic } \\
\text { Capacity } \\
\text { (MW) }\end{array}$ & $\begin{array}{c}\text { Solar } \\
\text { Thermal } \\
\text { Capacity } \\
\text { (MW) }\end{array}$ \\
\hline 1. & Rajasthan & 43 & 400 \\
\hline 2. & Gujarat & 722 & 45 \\
\hline 3. & Maharashtra & 133 & - \\
\hline 4. & Karnataka & 10 & - \\
\hline 5. & $\begin{array}{c}\text { Andhra } \\
\text { Pradesh }\end{array}$ & 20.5 & - \\
\hline 6. & Uttarakhand & 4 & - \\
\hline 7. & Punjab & 5 & - \\
\hline 8. & Haryana & 7.8 & - \\
\hline
\end{tabular}

\begin{tabular}{|c|c|c|c|}
\hline 9. & $\begin{array}{c}\text { Uttar } \\
\text { Pradesh }\end{array}$ & 11 & - \\
\hline 10. & Jharkhand & 16 & - \\
\hline 11. & Chhattisgarh & 4 & - \\
\hline 12. & $\begin{array}{c}\text { Madhya } \\
\text { Pradesh }\end{array}$ & 7.25 & - \\
\hline 13. & Odisha & 11 & - \\
\hline 14. & Tamil Nadu & 12 & - \\
\hline \multicolumn{2}{|c|}{ TOTAL } & 1006.55 & 445 \\
\hline
\end{tabular}

\section{CONCLUSION}

There is a marvelous potential in utilizing solar energy which can be converted coherently by using the technologies like PV cells and $\mathrm{T}$ panels or thermal collector for the conversion of solar power into electrical or heat energy respectively. To be more economical and feasible it can be achieved by using the system by combining two technologies for better efficiency and cost-cutting. The solar energy can also solve the problems of countries like India because as mentioned India is a tropical country where the solar energy is more than adequate, it can reduce the problems like shortage of electricity and thus by eliminating power cuts it would be more economical and efficient. We also looked into SBSP, the advantages and implementation issues related to it. Thus because of such availability, it would be greener and safer to use solar power as compared to utilizing electricity by burning fossils and harming the environment.

\section{REFERENCES}

[1] Sheikh, N. (2008). Efficient utilization of solar energy for domestic applications. 2008 Second International Conference on Electrical Engineering.

[2] Mousavi, S., Safavi, S., Naderlou, A., Shahmohammadi, H., Moshfegh, S., Tashakkori, P. and Shamipour, R. (2018). Important solar parameters in installing solar cells: Case study of Zanjan city in Iran. 2018 5th International Conference on Renewable Energy: Generation and Applications (ICREGA).

[3] Raval, R. and Choubey, S. (2017). Calculation and modeling of hybrid power generation system using solar energy. 2017 International Conference on Intelligent Sustainable Systems (ICISS).

[4] Sun, Honghang \& Zhi, Qiang \& Wang, Yibo \& Yao, Qiang \& Su, Jun. (2014). China's solar photovoltaic industry development: The status quo, problems and approaches. Applied Energy. 118. 221-230. 10.1016/j.apenergy.2013.12.032.

[5] Dimroth, F., Baur, C., Bett, A., Kostler, W., Meusel, M. and Strobl, G. (2006). Thin 5-Junction Solar Cells with Improved Radiation Hardness. 2006 IEEE 4th World Conference on Photovoltaic Energy Conference.

[6] Patel, S. and Rao, K. (2016). Social acceptance of solar energy technology in India. 2016 International Conference on Energy Efficient Technologies for Sustainability (ICEETS).

[7] Vidanalage, I. and Raahemifar, K. (2016). Tilt angle optimization for maximum solar power generation of a 
solar power plant with mirrors. 2016 IEEE Electrical Power and Energy Conference (EPEC).

[8] Swarnkar, N. and Gidwani, L. (2017). Economic and financial assessment of integrated solar and wind energy system in Rajasthan, India. 2017 International Conference on Computation of Power, Energy Information and Commuincation (ICCPEIC).

[9] Thomas, J., Ashok, S. and Jose, T. (2011). A hybrid pricing strategy for solar energy. International Conference on Sustainable Energy and Intelligent Systems (SEISCON 2011).

[10] Darshana, M., Karnataki, K., Shankar, G. and Sheela, K. (2015). A practical implementation of energy harvesting, monitoring and analysis system for solar photo voltaic terrestrial vehicles in Indian scenarios: A case of pilot implementation in the Indian Railways. 2015 IEEE International WIE Conference on Electrical and Computer Engineering (WIECON-ECE).

[11] Thorat Ashwini, Prof. Katariya S. S., Solar Power Satellite. IOSR Journal of Electronics and Communication Engineering (IOSR-JECE) ISSN: 22782834, ISBN: 2278-8735, PP: 59-64

[12] Richardson, L. (2018). The 5 Most Common Uses of Solar Energy in 2018 | EnergySage. [Online] Solar News. Available at: https://news.energysage.com/mostcommon-solar-energy-uses/

[13] Eai.in. (2018). Solar Energy in India | Solar policy of India, Solar companies, Capital incentives - EAI.in. [Online] Available http://www.eai.in/ref/ae/sol/sol.html 